\title{
Propriétés coagulantes et protéolytiques de la protéase extraite de Cirsium arvense
}

\author{
par \\ S. POZNANSKI, A. REPS, ELZBIETA DOWLASZEWICZ \\ Institut du Génie et de la Biotechnologie Alimentaire \\ Université Agricole d'Olsztyn \\ Directeur de 1'Institut : professeur agrégé Dr habil. S. PozNANSKI
}

\section{Rés u m é}

Un procédé permettant d'obtenir, à partir du Cirsium arvense, un extrait enzymatique de C-protéase coagulant a été décrit. On a déterminé les propriétés physiques, chimiques et biochimiques de cet extrait en les comparant avec les propriétés correspondantes de la présure. La C-protéase s'est montrée la plus stable à la chaleur de toutes les enzymes coagulantes connues jusqu'à ce jour. A des températures comprises entre $30^{\circ} \mathrm{C}$ et $50^{\circ} \mathrm{C}$ l'enzyme obtenue se comportait d'une manière semblable à celle de la présure ; pourtant, elle révélait des propriétés protéolytiques marquées au-dessus de $50^{\circ} \mathrm{C}$ et, à partir de $60^{\circ} \mathrm{C}$, l'augmentation de l'azote non protéique devenait proportionnelle au temps. L'aptitude de la C-protéase à hydrolyser les protéines à $100^{\circ} \mathrm{C}$ environ peut rendre de grands services. Le Cirsium arvense représente une matière première peu coûteuse et facile à se procurer pour la production d'une préparation enzymatique.

\section{INTRODUCTION}

Les protéases d'origine végétale qui possèdent le pouvoir de coaguler le lait se trouvent dans les fruits, les feuilles et même dans les semences de beaucoup d'espèces de plantes.

Les propriétés coagulantes des extraits de Ficus carica (ficine) et de Carica papaya (papaïne) étaient déjà connues dans l'antiquité. Certains de ces extraits étaient employés pour la coagulation du lait en vue de la fabrication des fromages. Demourov et Inichow (1962) ont étudié un grand nombre de plantes qui poussent en U.R.S.S. et 
en ont trouvé une centaine environ qui contiennent une enzyme coagulant le lait.

Le déficit de plus en plus sensible de présure provenant des caillettes de jeunes ruminants a attiré notre attention sur les possibilités offertes par les enzymes d'origine végétale.

Krishnamurthy et al. (1950), Dastur (1949), Krishnaswamy et Johar (1960) ont comparé les différences observées au cours de l'affinage du Cheddar entre un fromage fabriqué à l'aide de ficine et un fromage fabriqué avec de la présure. Dans la plupart des fabrications utilisant la ficine, les fromages obtenus avaient un goût un peu amer qui s'observait surtout pendant la période finale de l'affinage. On a constaté aussi que la consistance des fromages qui avaient été fabriqués avec la ficine était devenue fragile et grumeleuse après 5 semaines d'affinage (Inichow, 1962 ; Krishnaswamy, 1960).

On manque de données précises pour caractériser les propriétés des enzymes coagulantes d'origine végétale. De même, des renseignements manquent concernant les plantes communes des climats tempérés de l'hémisphère Nord qui contiennent des enzymes coagulant le lait.

Notre expérimentation a pour but de présenter les propriétés physiques, chimiques et biochimiques de l'extrait de Cirsium arvense, et de les comparer avec celles de la présure.

\section{PROTOCOLE EXPERIMENTAL}

Cirsium arvense était récolté dans les prairies et dans les champs cultivés, avant et pendant la période de floraison. Les extraits étaient préparés à partir des feuilles sèches en effectuant une macération du mélange homogénéisé dans un tampon acétate $0,01 \mathrm{M}$, à $\mathrm{pH} 4,6,5,6,6,6,7,6$ ou dans l'eau distillée. Une partie en poids de feuilles était homogénéisée avec 10 volumes de tampon ou d'eau. La macération durait $7 \mathrm{j}$ à une température comprise entre $0^{\circ} \mathrm{C}$ et $2^{\circ} \mathrm{C}$. Le liquide était alors centrifugé et le surnageant filtré sur un filtre Seitz retenant les bactéries. On obtenait ainsi un filtrat limpide, présentant une coloration brun clair.

\section{TECHNIQUES ANALYTIQUES}

Pour déterminer les caractéristiques de la préparation, les facteurs suivants ont été étudiés : température optimum de coagulation du lait ; relation entre la durée de coagulation et la quantité d'enzyme; durée de coagulation en fonction de la proportion de C-protéase et de présure dans un mélange de ces deux enzymes ; 
développement de la fermentation lactique au cours de la coagulation du lait ; cinétique de l'augmentation de la teneur en azote, calcium et phosphore dans le lactosérum pendant la coagulation du lait ; cinétique de l'augmentation de la teneur en azote soluble à pH 4,6 et de la teneur en azote non protéique (soluble dans l'acide trichloracétique à $12 \mathrm{p} .100$ ) ; différence de teneur en azote non protéique à la température de coagulation du lait entre $30^{\circ} \mathrm{C}$ et $50^{\circ} \mathrm{C}$ et pouvoir protéolytique à $75^{\circ} \mathrm{C}$ à $\mathrm{pH} 6,5$ et 5,0 et à diverses dilutions. A l'exception du pouvoir protéolytique, les résultats de toutes ces déterminations étaient comparés avec ceux des déterminations analogues effectuées avec la présure.

\section{RESULTATS ET DISCUSSION}

On a constaté que la préparation obtenue à partir du Cirsium arvense récolté dans les champs cultivés contenait beaucoup plus d'enzyme coagulante que celle obtenue à partir de la plante récoltée dans les prairies. Les résultats sont rassemblés dans le tableau 1. Les données ont été exprimées en unités présure par $\mathrm{ml}$ de la solution d'après Berridge (1955).

TABLEAU 1

\begin{tabular}{|c|c|c|c|c|}
\hline \multirow{3}{*}{$\begin{array}{l}\mathrm{pH} \text { de la } \\
\text { macération }\end{array}$} & \multicolumn{2}{|c|}{$\begin{array}{l}\text { Cirsium arvense } \\
\text { des champs cultivés }\end{array}$} & \multicolumn{2}{|c|}{$\begin{array}{c}\text { Cirsium arvense } \\
\text { des prairies }\end{array}$} \\
\hline & avant & pendant & avant & pendant \\
\hline & \multicolumn{2}{|c|}{ la floraison } & \multicolumn{2}{|c|}{ la floraison } \\
\hline Tampon 4,6 & 0,111 & néant & néant & néant \\
\hline Tampon 5,6 & 0,222 & néant & néant & néant \\
\hline Tampon 6,6 & 0,111 & néant & 0,030 & néant \\
\hline Tampon 7,6 & 0,028 & 0,020 & 0,010 & néant \\
\hline Eau distillée & 0,111 & 0,010 & 0,010 & néant \\
\hline
\end{tabular}

Les résultats du tableau 1 montrent que l'activité d'une préparation dépend non seulement de l'origine des plantes, mais surtout de l'époque de la récolte. En outre, l'activité la plus élevée était obtenue à partir des feuilles de Cirsium arvense récolté dans les 
champs avant floraison, par macération dans le tampon acétate à pH 5,6. C'est pourquoi les expériences ultérieures ont été effectuées avec la préparation de C-protéase obtenue à partir du Cirsium arvense récolté avant floraison.

\section{Figure 1}

La figure 1 montre que, contrairement à ce qu'on observe avec la présure, l'activité coagulante de la C-protéase augmente à mesure que la température s'élève et ceci jusqu'à $98^{\circ} \mathrm{C}$, cette température étant la plus élevée qui ait été employée au cours de notre expérimentation. De $30^{\circ} \mathrm{C}$ à $40^{\circ} \mathrm{C}$ l'augmentation d'activité de la C-protéase est à peu près linéaire, l'augmentation maximum étant précisément celle observée entre $30^{\circ} \mathrm{C}$ et $40^{\circ} \mathrm{C}$; entre $80^{\circ} \mathrm{C}$ et $98^{\circ} \mathrm{C}$ l'augmentation est très faible. La durée de coagulation du lait à $68^{\circ} \mathrm{C}$ étant de $100 \mathrm{~s}$ environ, on peut penser qu'au-dessus de cette température l'enzyme flocule le lait plus rapidement qu'il n'est inactivé. C'est pourquoi on a réduit la quantité d'enzyme ajoutée au lait (temps de coagulation de $220 \mathrm{~s}$ à $68^{\circ} \mathrm{C}$ ), mais malgré cela, l'enzyme continue

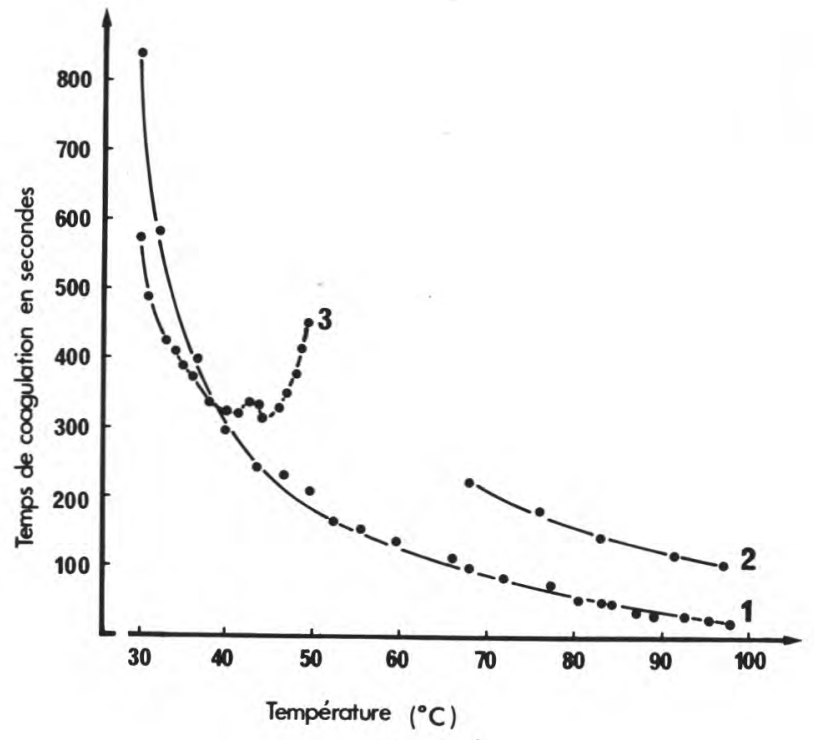

fig. 1

Coagulation du lait par la C-protéase et la présure en fonction de la température.

1. C-protéase.

2. C-protéase (dose moitié de 1).

3. Présure. 
à résister à l'inactivation (courbe 2). Ainsi, parmi toutes les enzymes coagulantes (Behnke, 1967 ; Poznanski et al., 1969 ; Reps et al., 1970 ; Tsugo et al., 1959) connues, la C-protéase paraît être la plus stable à la chaleur.

Figure 2

L'activité coagulante de la C-protéase en fonction de l'acidité $\mathrm{du}$ lait diffère sensiblement de celle de la présure. Sous ce rapport l'enzyme en question ressemble plutôt à la ficine (Cuckermann, 1961).

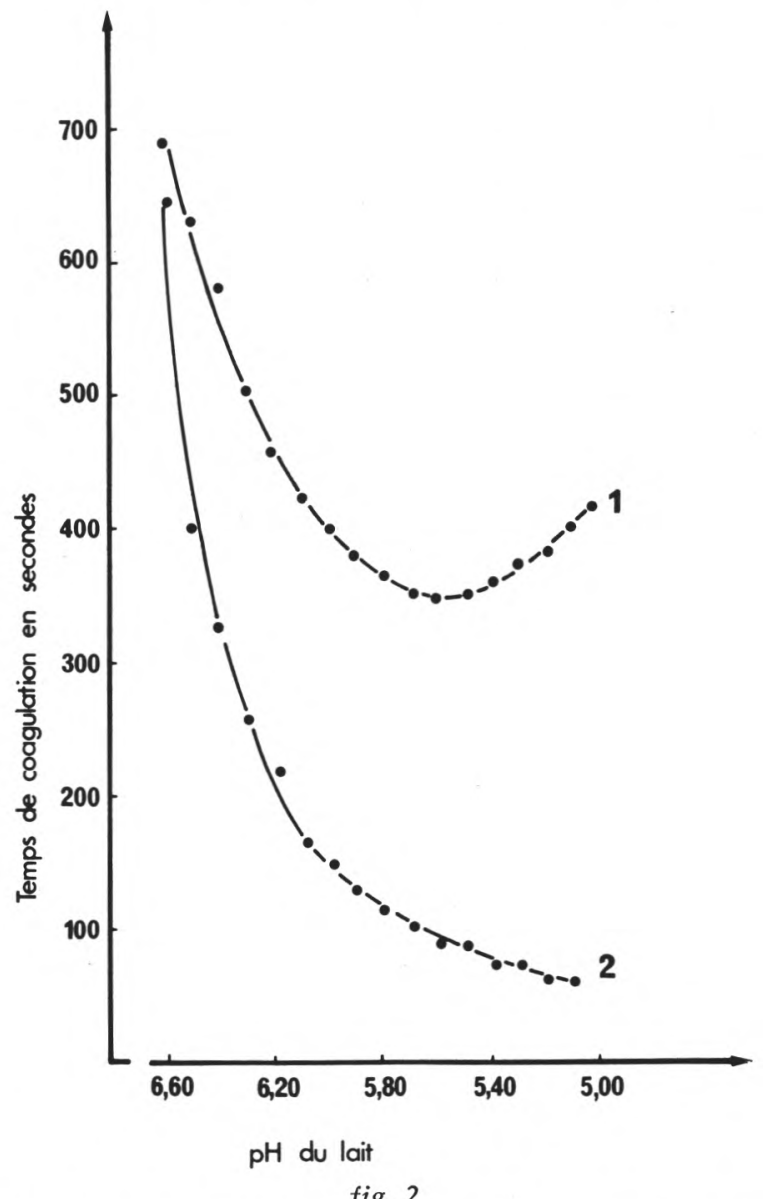

Influence du $\mathrm{pH}$ du lait sur l'activité coagulante de la C-protéase et de la présure.

1. C-protéase.

2. Présure. 


\section{Figure 3}

Bien qu'avec un mélange de C-protéase et de présure, la durée de coagulation du lait soit raccourcie au fur et à mesure que le $\mathrm{pH}$ du lait diminue, cette réduction est beaucoup plus lente que dans le cas où le lait est additionné de présure seule. Lorsqu'on augmente, dans le mélange "présure / C-protéase ", la proportion de C-protéase, la réaction de ce mélange au changement de $\mathrm{pH}$ du lait devient de plus en plus faible. A cet égard les propriétés de la C-protéase ressemblent à celles de la pepsine (Poznanski et al., 1969), ou bien à celles des protéases de Byssochlamys fulva et d'Endothia

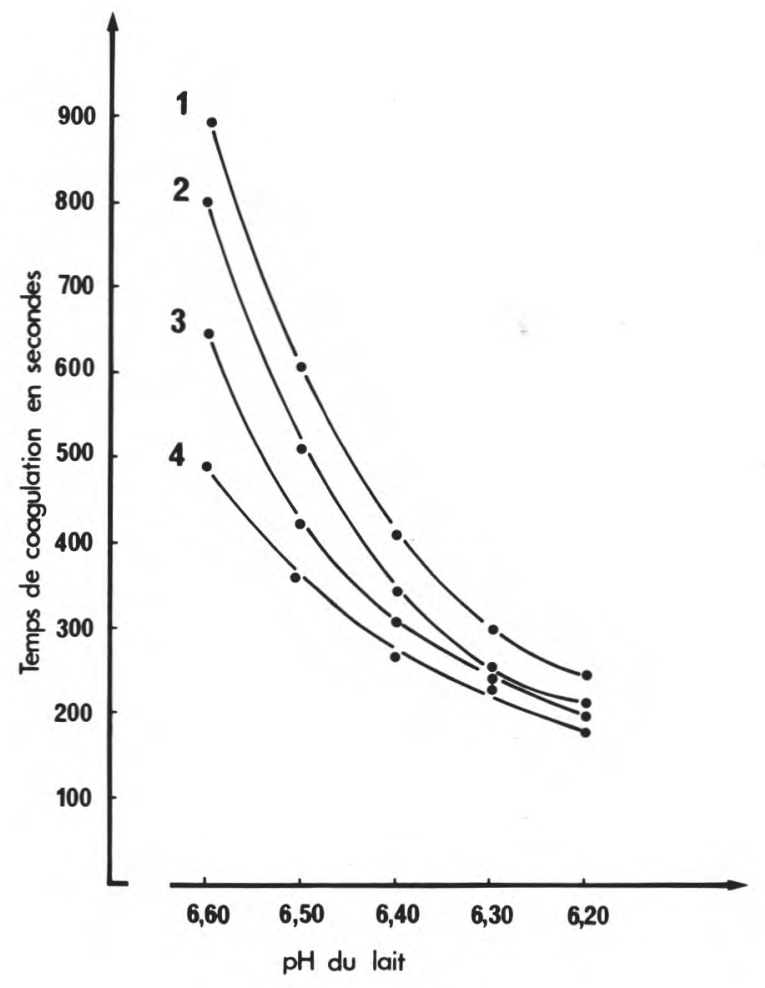

fig. 3

Temps de coagulation du lait en fonction du $\mathrm{pH}$ du lait et de la quantité de C-protéase ajoutée à la présure.

1. Présure.

2. Présure + C-protéase.

3. Présure + quantité double de C-protéase.

4. Présure + quantité triple de C-protéase. 
parasitica (Reps et al., 1970). On sait qu'il existe dans le cas de la présure, une relation entre la quantité d'enzyme (m) et la durée de coagulation du lait $(\mathrm{t})$ à $35^{\circ} \mathrm{C}(\mathrm{I}=\mathrm{mxt}=$ const.) (Poznanski et al., 1969 ; Reps et al., 1970 ; Tsugo et al., 1959).

\section{Figure 4}

$\mathrm{Au}$ cours de cette expérience la valeur du produit $\mathrm{m} \times \mathrm{t}$ diminue pour la C-protéase à mesure que la quantité d'enzyme ajoutée au

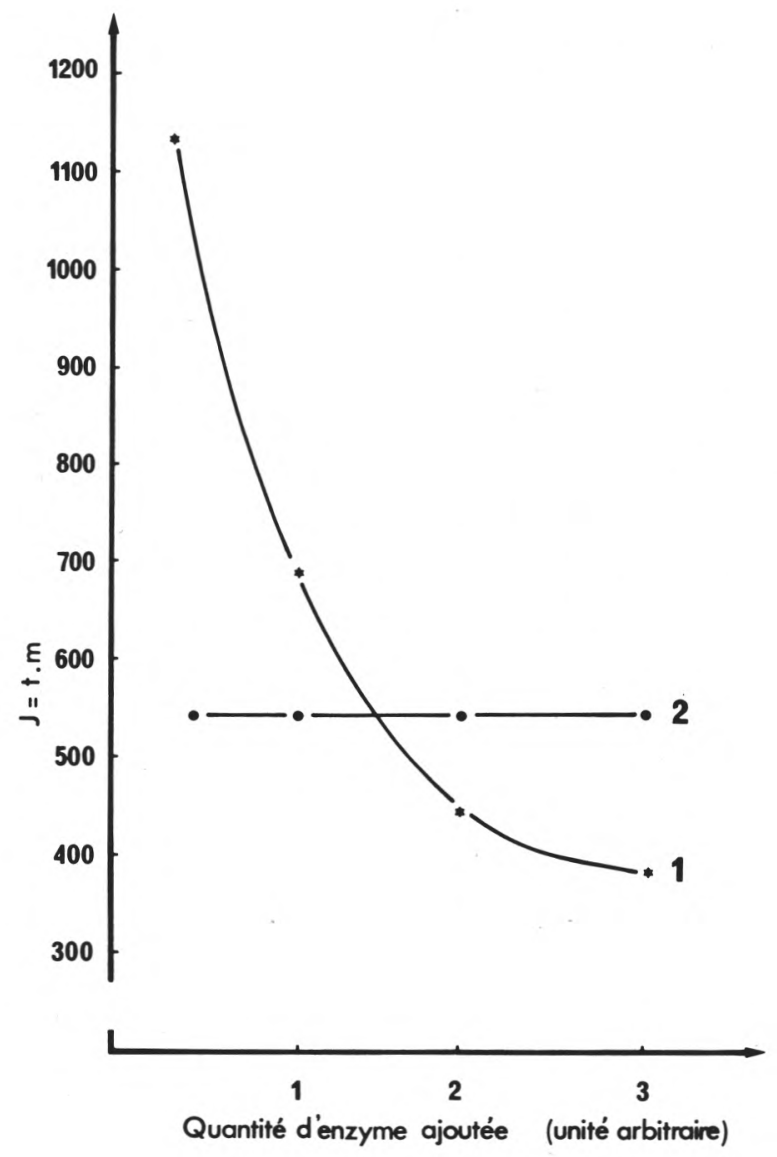

fig. 4

Relation entre le produit $\mathrm{txm}$ (temps de coagulation $\mathrm{x}$ quantité d'enzyme) et la quantité d'enzyme ajoutée.

1. C-protéase.

2. Présure. 
lait augmente. Nos observations sont en accord avec celles que Tsugo et al. (1969) et nous-mêmes (Reps et al., 1970) avions faites précédemment avec d'autres enzymes coagulantes.

\section{Figure 5}

En observant le temps de coagulation par des mélanges de solutions de présure et de C-protéase, en proportions différentes, mais avec des activités semblables on a constaté de nouveau que le temps de coagulation s'allonge considérablement, lorsqu'une partie de la présure est remplacée par la C-protéase.

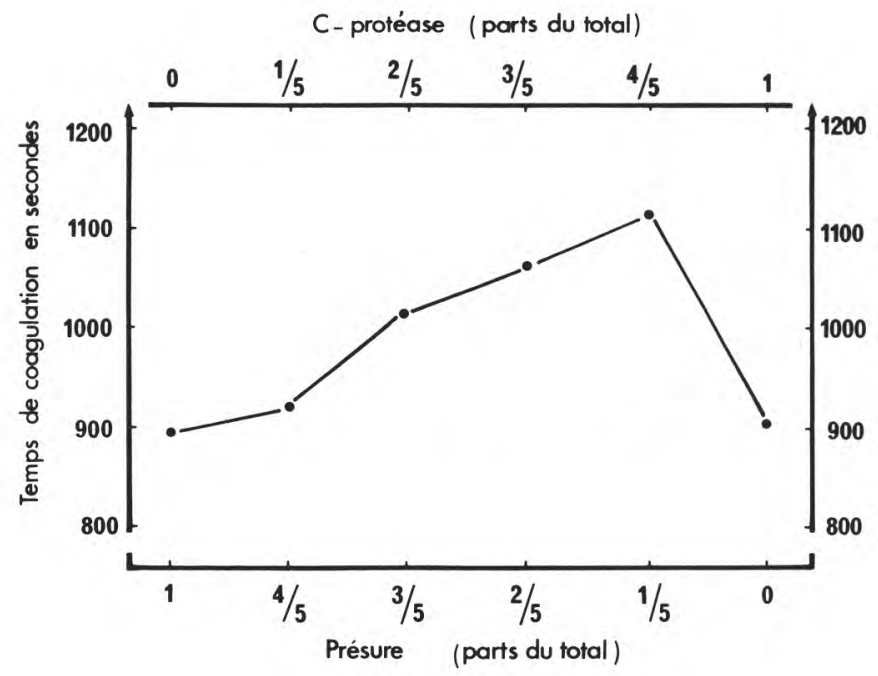

fig. 5

Temps de coagulation du lait par des mélanges de présure et C-protéase.

\section{Figure 6}

Comme c'était le cas avec des préparations coagulantes que nous avions obtenues à partir des moisissures (Reps et al., 1970), la préparation de C-protéase n'exerce aucune influence sur la cinétique de l'augmentation d'acidité, ce qui indique que cette préparation ne contient pas de substances inhibant ou activant le développement des bactéries lactiques. 


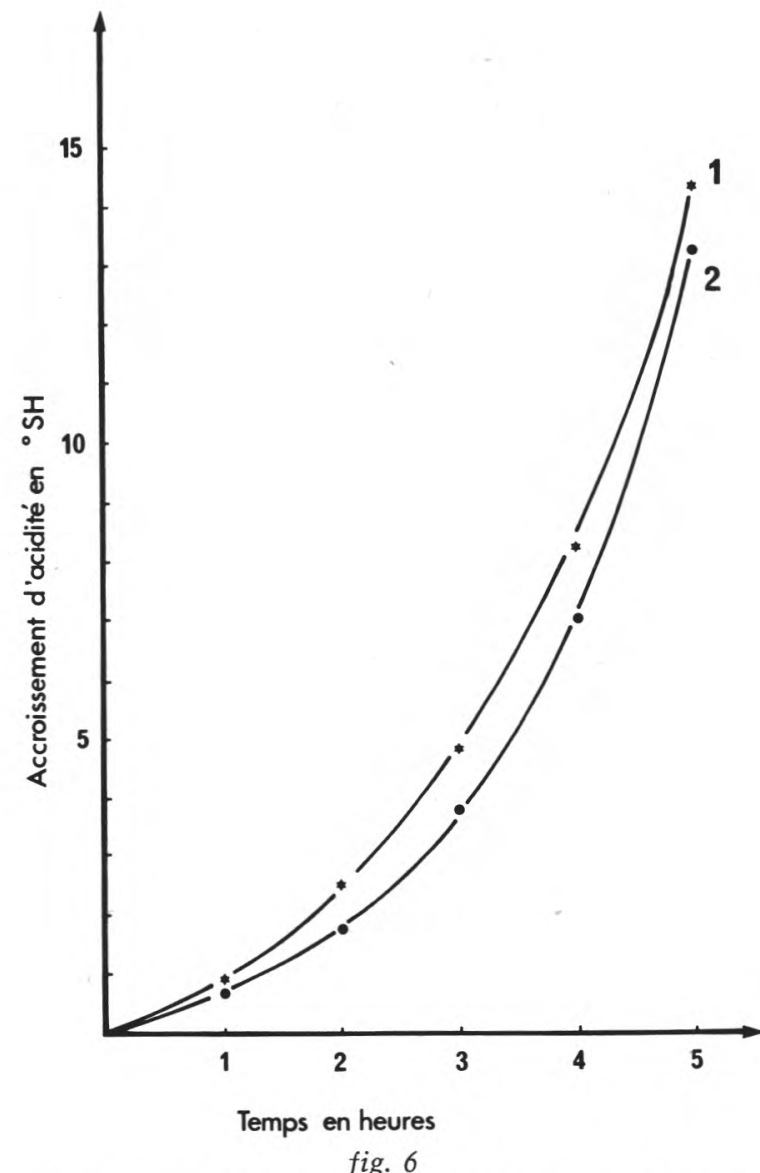

Accroissement de l'acidité du lait coagulé par la présure et la C-protéase en fonction du temps.

1. C-protéase.

2. Présure.

Figure 7

En déterminant la teneur en azote total et en azote non protéique du lactosérum après un temps défini de contact de l'enzyme avec le caillé $(30,60,90$ et $120 \mathrm{mn})$ nous avons constaté des différences au désavantage de la C-protéase. Tandis que la présure n'effectue pas d'hydrolyse appréciable pour les durées considérées, la C-protéase montre une certaine activité protéolytique. Plus grandes encore sont les différences observées en ce qui concerne l'augmentation de l'azote soluble à $\mathrm{pH}$ 4,6. La C-protéase libère des quantités beaucoup plus élevées de substances azotées solubles à $\mathrm{pH}$ 4,6 que ne le fait la présure figure 8. 


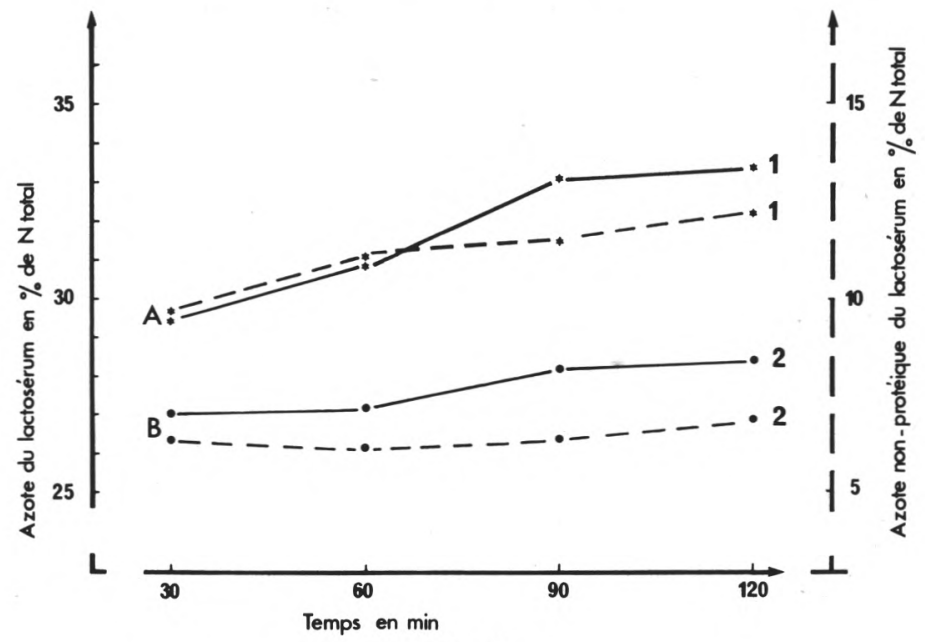

fig. 7

Teneur en azote soluble et non protéique du lactosérum après $2 \mathrm{~h}$ de contact du lait avec l'enzyme. 1. C-protéase.

2. Présure.

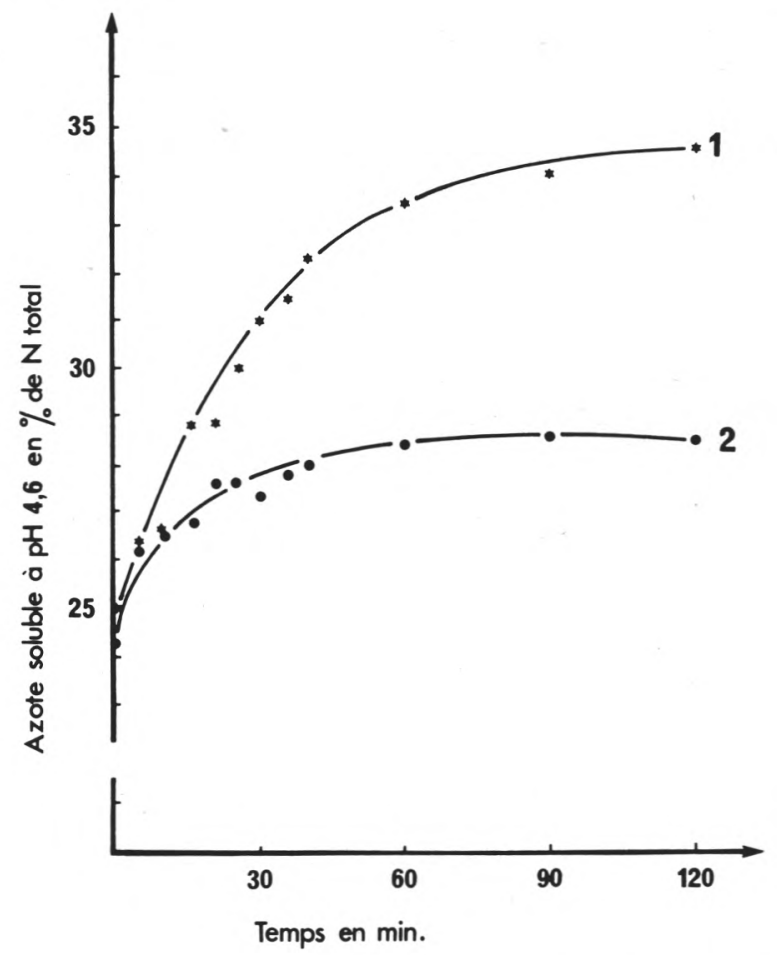

fig. 8

Accroissement de l'azote soluble à $\mathrm{pH} 4,6$ pendant $2 \mathrm{~h}$ de contact du lait avec les enzymes étudiées.

1. C-protéase.

2. Présure. 
Par contre, aucune différence essentielle n'est observée quant à la teneur en calcium et en phosphore du lactosérum obtenu après la coagulation du lait, soit par la présure, soit par la C-protéase. De telles différences ont cependant été observées par Tsugo et Yamauchi (1959) dans le cas des enzymes d'origine microbienne.

\section{Figure 9}

Cette figure représente la cinétique de l'augmentation de l'azote non protéique due à l'addition au lait de présure, de C-protéase à

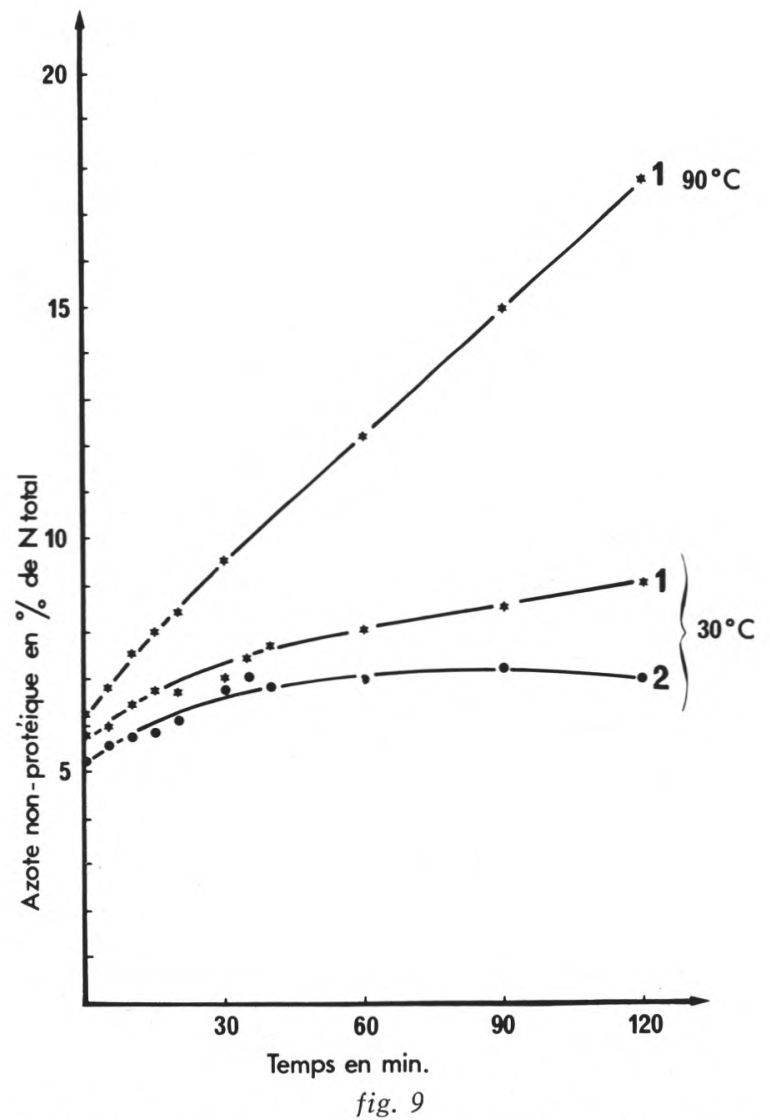

Accroissement de l'azote non protéique pendant $2 \mathrm{~h}$ de de contact du lait avec les enzymes étudiées.

1. C-protéase.

2. Présure. 
$30^{\circ} \mathrm{C}$ et de $\mathrm{C}$-protéase à $90^{\circ} \mathrm{C}$. A la température de $30^{\circ} \mathrm{C}$ l'augmentation de l'azote non protéique est, pour la C-protéase, plus élevée de 2 p. 100 par comparaison avec la présure, après $120 \mathrm{mn}$ de contact de la C-protéase avec le lait, tandis qu'on constate l'augmentation linéaire de cette forme d'azote à $90^{\circ} \mathrm{C}$.

\section{Figure 10}

La figure 10 indique que la C-protéase se comporte de la même manière que la présure, lorsque la coagulation du lait a lieu entre $30^{\circ} \mathrm{C}$ et $50^{\circ} \mathrm{C}$, tout en révélant un fort pouvoir protéolytique au-dessus de $50^{\circ} \mathrm{C}$. A partir de $60^{\circ} \mathrm{C}$ l'augmentation de l'azote non protéique est proportionnelle au temps.

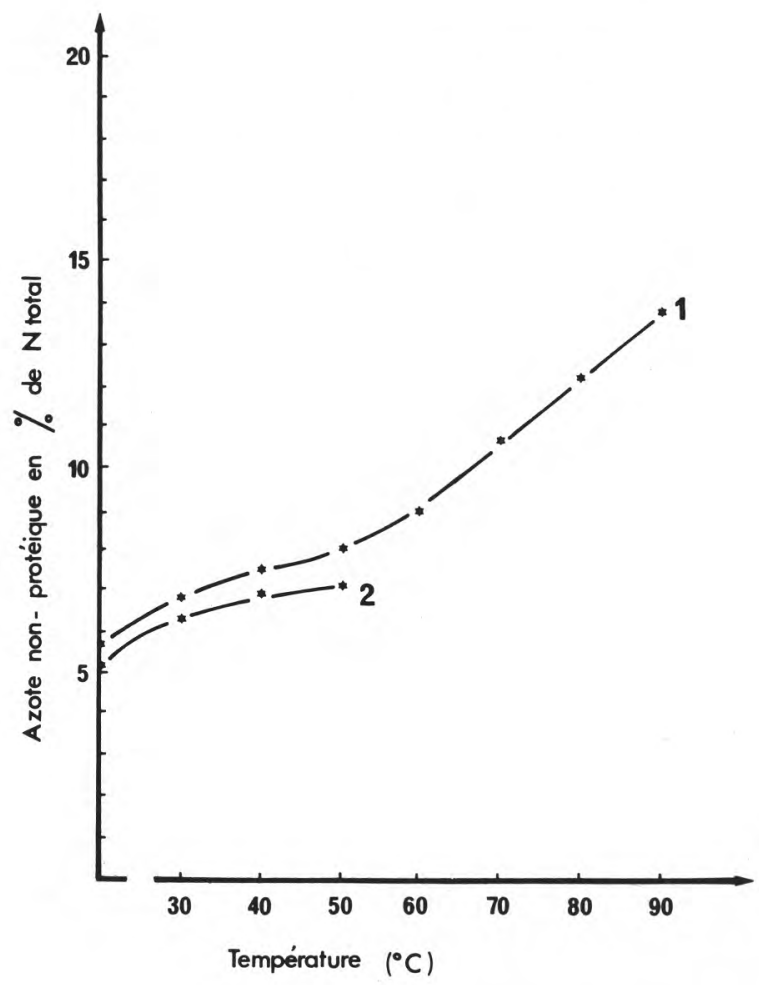

fig. 10

Libération d'azote non protéique en fonction de la température par la présure et la C-protéase.

1. C-protéase

2. Présure. 


\section{Figure 11}

Enfin, nous avons étudié l'aptitude à la dégradation des protéines du lait à la température d'incubation de $75^{\circ} \mathrm{C}$. Comme on le voit sur la figure 11, la quantité de protéines dégradées sous forme d'azote non protéique atteint 88 p. 100 , quels que soient le $\mathrm{pH}$ et le degré de dilution du lait. On peut noter cependant que l'équilibre s'établit plus rapidement pour le lait incubé à $\mathrm{pH} 5,0$ et dilué de façon à atteindre une teneur en protéines de 1 p. 100 environ. La propriété que possède la C-protéase d'hydrolyser les protéines à $100^{\circ} \mathrm{C}$ environ peut rendre de grands services pour prévenir le développement d'une microflore indésirable. En quelques heures, la préparation de C-protéase peut libérer 60 p. 100 environ d'azote non protéique des bactéries et des moisissures. D'autre part le Cirsium arvense représente une matière première peu coûteuse et facile à se procurer pour l'obtention de la préparation enzymatique.

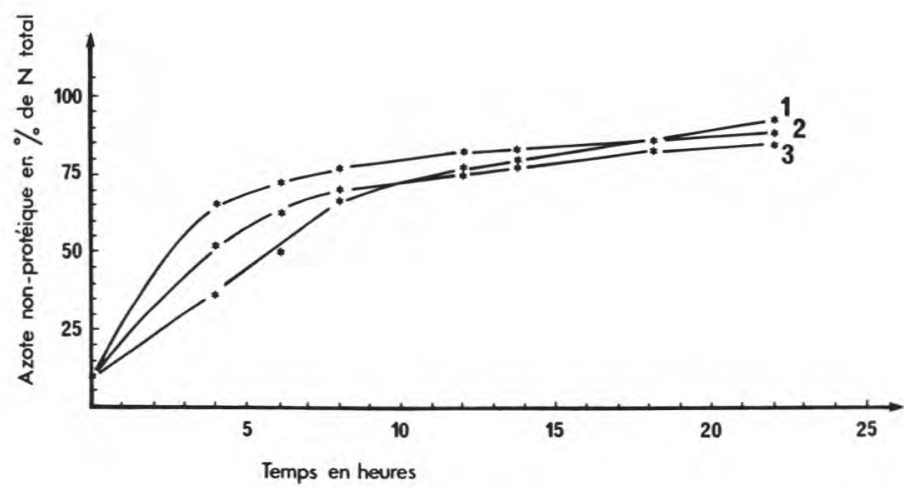

fig. 11

Degré de dégradation des protéines du lait par la C-protéase en fonction du temps à $75^{\circ} \mathrm{C}$.

1. Lait à $\mathrm{pH} 6,5$.

2. Lait dilué à $\mathrm{pH} 5,0$.

3. Lait dilué à $\mathrm{pH} 6,5$.

\section{S u m m a r y}

\section{CLOTTING AND PROTEOLYTIC PROPERTIES OF CIRSIUM ARVENSE}

A procedure for the preparation of an enzyme extract of Cirsium arvense showing milk coagulating ability has been described. Physical, chemical and biochemical properties of this extract were determined and comparisons were made with the corresponding properties of 
rennet. Of all milk coagulating enzymes, which are known at present, C.protease was found to be the most heat stable. Within the range of temperature between $30^{\circ} \mathrm{C}$ and $50^{\circ} \mathrm{C}$, the enzyme obtained (C-protease) behaved in the same manner as rennet, but above $50^{\circ} \mathrm{C}$ it showed a strong proteolytic action, and starting at $60^{\circ} \mathrm{C}$, upwards, the increase of non protein nitrogen became directly proportional to the time. The ability of C-protease to hydrolyze proteins at about $100^{\circ} \mathrm{C}$ may appear to be very useful, and Cirsium arvense may represent a cheap and commonly available raw material for this type of enzyme preparation.

\section{Références bibliographiques}

BEHNKE (V.) (1967). - Untersuchungen zur Wirkung von Labpreparaten verschiedener Herkunft. Milchwissenschaft, 22, 563.

Berridge (N. J.) (1955). - Purification and assay of rennin. Methods in enzymology VIJ (Colowick P.S., Kaplan N. O.). Academic Press Inc., New-York.

Cuckermann-Stark (S.), Leibowitz (J.) (1961). - Researches on milk clotting enzymes from palestinian plant sources. D.S.A., 23, 2666.

Dastur (N. N.) (1949). - Milk clotting enzymes from plants. D.S.A., 11, 105.

INIcHow (G. S.) (1962). - Biochimia malaka i molocznych produktow. Piszczepromizdat, Moskwa.

Krishnamurthy (G. V.), Subrabmanyan (N.) (1950), - Studies on vegetable rennet. Part II. Vegetable rennet from streblus asper and preparation of cheese using vegetable rennets. D.S.A., 12, 196.

Krishnaswamy (M. A.), Johar (D. S.) (1960). - Studies on the use of the milk clotting enzyme from Ficus carica (Linn.) for the manufacture of a Nord type of vegetable cheese. D.S.A., 22, 325.

Reps (A.), Poznanski (S.), Kowalska (W.) (1970). - Characteristics of milk coagulating proteases obtained from Byssochlamys fulva and Endoth:a parasitica. Milchwissenschaft, 25, 146.

PoznANSKi (S.), RePs (A.), Smietana (Z.) (1969). - Otrzymywanie, charakterystyka i proby zastosowania ekstraktu pepsyny do koagulacji mleka przy wyrobie sera. Zesz. Nauk. W.S.R. Olsztyn, 22, 681, 319.

Tsugo (T.), Yamauchi (K.) (1959). - Comparison of clotting action of various milk coagulating enzymes. I. Comparison of factors affecting clotting time of milk. XVth Int. Dairy Congress, 2. 